\title{
A TROCA DAS PALAVRAS E A TROCA DAS COISAS. POLÍTICA E LINGUAGEM NO CONGRESSO NACIONAL ${ }^{*}$
}

Luiz Eduardo Abreu

\section{Introdução}

A história é conhecida (ou pelo menos era à época). Os telefones do ministro das Comunicações, Mendonça de Barros, foram "grampeados" (ilegalmente, diga-se) durante o processo de venda das empresas de telefonia do governo, e algumas frases dessas conversas vieram a público algum tempo depois, causando grande alvoroço. A ilegalidade das gravações não impediu seu impacto político. No dia 6 de novembro de 1998, o ministro foi apresentar "explicações" aos senadores — da capacidade de convencimento do ministro dependia sua permanência no ministério (conforme se dizia) - e tudo foi por água abaixo com a seguinte repreensão do senador Pedro Simon: "V. Ex. ${ }^{a}$ está equivocado quando diz: 'Eu quero que me condenem por atos e não por palavras'. As palavras, em política, são importantes... Eu lhe digo do fundo do coração, eu, se fosse V. Ex. ${ }^{a}$, renunciava. Se eu fosse V. Ex. ${ }^{a}$ praticava um gesto de grandeza, ajudava o Presidente da República" ${ }^{1}$.

As palavras do senador apresentam, pelo momento, pelos acontecimentos e pelas conseqüências, o dilema político na sua versão mais contundente: se as palavras são traiçoeiras, elas são também inevitáveis. O político sabe perfeitamente que tudo poderia ser de outro jeito e que as palavras de hoje podem ser os fatos de amanhã. Mas, de alguma forma, nos adiantamos. Antes de entrar na etnografia dessa linguagem é necessário começar por uma questão menos empolgante, embora mais fundamental: como relacionar a afirmação do senador — tomada como o dado etnográfico que descortina o papel das palavras nesse campo social - com a prática e a teoria antropológicas, quer dizer, com a nossa maneira de perceber o fenômeno?

A relação da linguagem com a antropologia, naquilo que interessa a este texto, vincula-se, de uma maneira ampla, a duas considerações mais 
gerais. Primeiro, a linguagem, os seus limites e a maneira como o antropólogo "relaciona-se" com ela são questões presentes em qualquer trabalho etnográfico, questões que fazem parte de um fazer. Algumas vezes, no entanto, nossa atenção dirige-se explicitamente à linguagem - seja por conta de preocupações teóricas, seja por conta da própria experiência etnográfica. E o ponto que convém enfatizar é o seguinte: se a linguagem é o foco central deste trabalho, é porque as preocupações esboçadas ao longo do texto, de alguma forma, já estão presentes na, digamos, "sabedoria" empírica da política e dos políticos no Congresso Nacional. Segundo, a política no Congresso Nacional é entendida pelos seus participantes como relações de troca, nas quais fazem parte - mesmo quando não haja nisso senão engodo e mentira social (para utilizar a expressão de Mauss) — os aspectos clássicos da dádiva, a saber: o aparente desinteresse simultâneo à expectativa da reciprocidade futura, a pessoalidade, o desequilíbrio social estabelecido pela prestação e outros que aparecerão ao longo do texto. A identificação da troca com a linguagem surge, na antropologia, a partir da leitura que Lévi-Strauss (1968) faz do "Ensaio sobre a dádiva" (Mauss 1968). Lévi-Strauss argumentava, então, que a sociedade é baseada na troca - a troca das palavras, das mulheres e das coisas - e que a troca era, ela também, uma forma de comunicação; daí, ele propôs que o modelo da linguagem fornece o paradigma para compreender a troca e, por conseguinte, a sociedade. O resultado da pesquisa no Congresso Nacional aproveita a intuição de Lévi-Strauss para segui-la em uma direção, em certo sentido, oposta.

\section{Considerações sociológicas preliminares}

O fato de os participantes da política verem suas relações como relações de troca que assumem, por assim dizer, o "registro" da dádiva não constitui uma novidade. Nisso, o Congresso Brasileiro nada mais faz do que espelhar a realidade social mais ampla na qual se insere. O fenômeno sequer é novo; ao contrário, já foi amplamente anunciado por autores de diferentes filiações teóricas (vide Abreu 1993, 1999; Bezerra 1999; Lanna 1995; Leal 1997; Palmeira 1996 etc.). Assim, não convém neste momento desenvolver o assunto longamente - a ele voltaremos repetidas vezes no decorrer do texto. A associação da política à linguagem, ao contrário, pode representar algumas dificuldades - principalmente para o nosso olhar que está, por assim dizer, "treinado" para perceber esses fenômenos a partir do conceito de poder. É portanto à questão da linguagem que esses comentários etnográficos preliminares se dirigem. 
Como tudo nesse mundo, a linguagem está vinculada à divisão que o meio social opera e estabelece como duas "realidades" distintas. De um lado, os aspectos que a teoria política reconheceria como "institucionais", quer dizer, as regras pertinentes ao funcionamento das seguintes instituições: Congresso Nacional, Senado Federal e Câmara dos Deputados; regras essas estabelecidas pela Constituição Federal, pelos regimentos internos, pelos diversos tipos de resoluções e por outras tantas leis, bem como os argumentos utilizados para falar dessas instituições ou a partir delas ${ }^{2}$. De outro, aquilo que, da perspectiva dos que participam dos eventos, estaria "de fato" acontecendo, isto é, o mundo de trocas, acordos, compromissos e interesses que se esconde atrás de portas fechadas — "nos bastidores", como se diz.

A idéia de caracterizar o sistema social brasileiro a partir da distinção e da oposição de duas categorias heterogêneas, diferenciadas de maneira absoluta, não é nova na literatura. Há, por exemplo, algumas semelhanças — um certo "ar de família" - entre os dados do Congresso e a distinção entre "ética pessoal" e "ética burocrática" de Da Matta (1997). De todo jeito, vamos nos utilizar da fórmula de Luiz Tarlei de Aragão (1990:62), para quem estaríamos "diante de uma sociedade, ou de um sistema social, que historicamente tem provado sua incapacidade de produzir uma articulação das diferenças e uma totalização do social", isto é, no contexto desta pesquisa, a incapacidade de construir uma articulação totalizante que contenha, simultaneamente, as regras da instituição e as práticas cotidianas a partir das quais ela se reproduz — "justamente porque o sistema social tem vivido essa separação ontogênica entre a dominação (a autoridade, o direito) e a posse (a imanência, a prática)" (Aragão 1990:62). É preciso ressaltar, contudo, que o objetivo aqui não é pensar tal distinção na sociedade brasileira em geral, mas tão somente as suas repercussões para o nosso assunto: a linguagem na política.

Tanto na atividade que acontece na órbita do regimento interno e da norma jurídica, quanto naquela que se desenrola nos bastidores, a linguagem é central para a política. Tal era no fundo a admoestação do senador Pedro Simon ao então ministro Mendonça de Barros. Quando este último afirma que queria ser condenado por atos e não por palavras, o que ele pretendia era, segundo a experiência do senador, colocar-se além da política, porque na política a distinção entre palavras e ação não faria sentido. Assim, os procedimentos regimentais pertencem todos à linguagem: os pareceres, os requerimentos, os projetos, os recursos e as proposições são ditas em voz alta, no momento determinado e, somente assim, podem ser eficazes e causar movimentos institucionais. E mesmo quando a palavra (tomada aqui no sentido lato) está aparentemente ausente, como na votação 
eletrônica no plenário, por exemplo, o voto eletrônico apenas substitui a declaração da vontade do deputado ou senador eleito, um "voto sim, sr. Presidente", por outra, eletrônica. Em um certo sentido, "parlamentar" é aquele que tem o direito à palavra, pode usá-la em determinadas ocasiões, com efeitos regulados pelos respectivos regimentos.

Da mesma forma, toda a atividade que está além das regras institucionais é também fundada na linguagem, dado etnográfico que encontra expressão colorida em várias passagens do folclore político, como o dito segundo o qual "conversa que dura menos do que quatro horas não é política"; ou o seguinte caso de Tancredo Neves, quando um jornalista lhe perguntou se ele não achava a atividade do Congresso meio enfadonha o jornalista referia-se à atividade sisuda e "ritualizada" dos procedimentos regimentais. Tancredo Neves respondeu que aquele é um "centro de criatividade" e exemplificou:

De vez em quando eu invento um boato e solto lá na entrada quando chego. Daí, passo rapidamente no meu gabinete e depois vou ao plenário. Sabe o que acontece? Encontro meu boato muito melhorado e, às vezes, já com um ou dois filhotes. Boatinhos novinhos em folha... (apud Couto 1995:34).

A face mais "evidente" do fenômeno é porém a distinção radical que o meio social opera entre a linguagem utilizada nos contextos regulados pelo regimento interno (e pela norma jurídica) e a linguagem empregada nos bastidores: são duas maneiras completamente diferentes de expressão, quanto ao vocabulário, à postura e à "intimidade". Quando as palavras são objeto de registro institucional ou em situações nas quais, embora isso não aconteça, o registro público seja considerado "normal", "legítimo", utilizamse os artigos do regimento interno, "V. Exª.", "nobre colega", argumentos baseados no consenso, na vontade da maioria, no melhor para o Brasil, no desinteresse pessoal, na lei. O exemplo "paradigmático" são as sessões do Plenário, nas quais a possibilidade de a palavra ter efeitos institucionais está vinculada ao uso "correto" deste vocabulário. Nos "bastidores", onde acontecem os acordos, as negociações, as trocas, os argumentos e os interesses que não são visíveis para o grande público, as conversas são coloquiais, soltas e freqüentemente se usam gírias ou palavrões. Esses dois aspectos do fenômeno político constituem-se, portanto, efetiva e analiticamente, de duas linguagens distintas quanto às regras, aos efeitos, à eficácia e aos contextos sociais nas quais se aplicam, fazem sentido.

Da perspectiva sociológica, porém, seria um erro de método tratá-las separadamente. Parafraseando Durkheim, quem escolhe uma como "a rea- 
lidade" e relega a outra à irrelevância está, no fundo, opondo abstrações. A realidade social está na difícil e conflituosa relação de ambas. Mas mesmo estabelecendo a precedência da relação como regra de método, a perspectiva sociológica tem de levar em consideração a maneira pela qual as duas linguagens são percebidas e elaboradas pela experiência desse campo social. E o dado etnográfico atesta que a percepção "nativa" contradiz o princípio do método sociológico. Com efeito, para aquele que vivencia essas duas linguagens como uma realidade cotidiana, elas são percebidas a partir da negação que uma opera em relação à outra, negação que assume, em cada uma delas, formas distintas, formas que dependem dos seus respectivos conteúdos e usos.

No caso da "linguagem regimental" (expressão, acredito, incorreta, mas que utilizo a bem da economia do texto), a negação da política enquanto "conversa" está relacionada à (e exemplificada pela) proximidade, dependência e semelhança desse tipo de linguagem com a jurídica. No plano mais evidente, uma proposição aprovada - toda matéria submetida à deliberação do Congresso, do Senado ou da Câmara é regimentalmente chamada de "proposição" — torna-se parte do sistema formado pelas normas jurídicas: são estas últimas que possibilitam que as proposições tenham desdobramentos e, ao mesmo tempo, limitam sua eficácia. Não é por outro motivo que todos os projetos de lei (ordinária ou complementar) e emendas à Constituição tenham de passar pela Comissão de Constituição e Justiça. Essa comissão verifica os "aspectos constitucional, legal, jurídico, regimental e de técnica legislativa de projetos, emendas ou substitutivos sujeitos à apreciação da Câmara ou de suas comissões", bem como a "admissibilidade de proposta de emenda à Constituição" (art. 32 do Regimento Interno da Câmara dos Deputados, o mesmo valendo para o Senado).

Em um plano menos evidente, o próprio funcionamento de cada uma dessas instituições está regulado por leis e princípios que se encontram formulados na linguagem jurídica como, por exemplo, no direito administrativo. Além disso, a atividade dos deputados está submetida, regimental e constitucionalmente, à figura do "decoro parlamentar" (para um estudo específico sobre o tema, vide Teixeira 1998). Inclusive, os deputados aprovaram, por meio da Resolução no 25 de 2001, o Código de Ética e Decoro Parlamentar da Câmara dos Deputados que "estabelece os princípios éticos e as regras básicas de decoro". Entre os deveres dos deputados encontram-se "exercer o mandato com dignidade e respeito à coisa pública e à vontade popular, agindo com boa-fé, zelo e probidade" e "encaminhar todas as proposições submetidas à sua apreciação e voto a partir da ótica do interesse público". No limite (visível, por exemplo, no Código de Ética e no Código Penal, nos 
Crimes Contra a Administração Pública), aquilo que não cabe na "linguagem regimental" é relegado à ilegitimidade, ilegalidade ou, no mínimo, à irrelevância. No que afeta mais de perto o argumento deste texto, a linguagem regimental nega a troca, a pessoalidade e a contingência; em outras palavras, nega aquilo que, para os participantes desse mundo, é o que realmente acontece e, em um certo sentido, nega a própria política.

Para os que vivem a política como atividade cotidiana, são os bastidores que servem para caracterizar o que, segundo sua experiência, é o "político". "Nos bastidores está toda a criatividade, a política de verdade", já me disseram.

Isto não significa que o regimento não deva ser conhecido, ignorado. Pelo contrário. Os deputados ou senadores que o conhecem bem têm uma grande vantagem diante daqueles que o desconhecem. Usar o regimento equivale aqui a dominar uma técnica, técnica cuja importância está na possibilidade de criar desdobramentos nos bastidores. Nesse sentido, o regimento é utilizado para impor obstáculos e "vender" soluções, ou para consolidar ou fazer valerem posições quaisquer. Ora, na medida em que os usos do regimento dependem de uma "realidade" que se encontra alhures, a linguagem dos bastidores nega o conteúdo da "linguagem regimental", toda a sua referencialidade própria; nega, enfim, a possibilidade desta última circunscrever, colonizar o mundo político.

A dupla negação e a distinção radical das regras entre a linguagem regimental e a linguagem dos bastidores pertencem aos dados etnográficos, correspondem à forma como - para usar a expressão de Aragão (1990) — a "separação ontogênica" entre a autoridade e o direito, de um lado, e a imanência e a prática, de outro, articula-se nesse meio social específico. No cotidiano da instituição, há muitas situações nas quais tal distinção não é tão clara, quer dizer, há zonas cinzentas, interstícios. E nos interstícios, às vezes, elas se misturam com conseqüências mais ou menos catárticas. Esta parece ter sido, no plano da sociologia de tais linguagens, a "razão" oculta do destino político do ministro Mendonça de Barros, razão pela qual a interpelação do senador Pedro Simon é não mais que uma parte. As palavras do ministro que deveriam ter permanecido nos bastidores, e talvez aí fossem consideradas "normais", entraram no mundo público dos jornais e da "linguagem regimental". Um fato assim não é banal. As palavras precisariam voltar aos seus devidos lugares, a confusão teria de ser desfeita e a distinção restabelecida - algo que somente um sacrifício (a execração pública do ministro) poderia realizar. Mas o ponto aqui não é que a "realidade social" corresponda, toda ela, à classificação esboçada acima ou, dizendo de outra forma, que a classificação seja exaustiva, mas sim que esta distinção faz 
parte da maneira pela qual os participantes da política elaboram e pensam o seu mundo e a experiência nele vivida.

A conseqüência do "mundo dividido" é jogar aquilo que acontece nos bastidores à sombra, recobri-lo de segredo, segredo este que se reflete em vários planos da realidade social, inclusive na sua morfologia: há, por exemplo, o lugar do segredo. Algumas lideranças dispunham de salas pequenas, sem janelas e com proteção acústica, chamadas de "confessionário" (os gabinetes dos senadores também têm proteção acústica). Mas mais importante para o nosso assunto, o segredo - as palavras ditas apenas para alguns, palavras que outros não podem ouvir - está imbricado na prática política à categoria de poder. "O poder do líder são os segredos de confissão que possui", já dizia um ex-líder e ex-presidente da Câmara.

O deputado entra na sala com seu líder e ali "abre o jogo", diz exatamente o que precisa e o porquê. Não faz sentido, por exemplo, ir ao confessionário para dizer "minhas bases precisam disso", mas para afirmar que "se não conseguir dinheiro para essa ponte, não vou me reeleger", ou "estou falido por causa da campanha; preciso fazer o presidente de tal órgão público". O papel do líder é aqui fazer a intermediação desses pedidos, "negociá-los" com o Executivo. Por um lado, ele conhece como os parlamentares da sua bancada expressam seus interesses ou necessidades; por outro, ele usa o peso dos votos do partido para "obter" coisas com o Executivo, dentre elas, as "demandas" da bancada. O líder é, portanto, um nó desse sistema de trocas, com uma característica muito particular: ele organiza no mesmo sistema a troca das palavras, a troca das coisas e a troca das palavras pelas coisas. De todo jeito, o que caracteriza algo como segredo é pertencer ao "regime fechado" da circulação das palavras e das coisas, regime que contém perigos e armadilhas difíceis de avaliar e que representam um drama sempre reencenado: Posso confiar naquilo que me dizem? Posso confiar-lhe esse segredo? Posso dizer essas palavras? Mas esse regime não deve ser compreendido sozinho, porque a sua realidade está na relação que mantém com um outro, um regime aberto de circulação das palavras que também opera nos bastidores. Já tivemos oportunidade de vislumbrar a circulação das palavras nesse regime aberto (o caso de Tancredo Neves acima). É o mundo do boato, do comentário anônimo, daquilo que "todo mundo sabe".

O problema etnográfico é que os dois sistemas estão em aparente oposição: guardar segredo significa manter certas palavras fora do circuito aberto de circulação das palavras. A questão é, portanto, como elaborar a relação entre eles. Para tanto convém examiná-los a partir da seguinte constatação etnográfica: para além das coisas que se trocam na política, trocam-se tam- 
bém o silêncio e as palavras. Via de regra, a situação poderia ser descrita da seguinte maneira: uns guardam dos outros segredos potencialmente comprometedores; dessa forma, uns dependem do silêncio dos outros ou, dizendo de maneira mais próxima àquela como eles mesmos percebem o fenômeno, eles trocam o silêncio pelo silêncio — ou por outras coisas. Todavia, como em toda regra, há sempre a possibilidade da sua violação. Algumas vezes, os segredos vêm a público, seja pelo acaso, seja pela ação de alguém (no caso do grampo do ministro, por exemplo, a questão relevante para os que estão nesse meio seria: Quem quebrou a regra não-escrita? Quem é o responsável por dar as fitas à imprensa?). Expor um segredo, contudo, não é perigoso apenas para aquele que o seu conteúdo prejudica; quebrar a regra do silêncio pode lá ter suas conseqüências para quem a infringe.

Por outro lado, também se trocam palavras, põem-se as palavras para circular. Dentre as palavras que se trocam, algumas descrevem - ou alegam descrever - o que se esconde nas sombras do segredo, porque é no segredo, segundo a sabedoria "nativa", que se encontra a razão e o sentido das ações alheias - aquilo que é preciso saber, mas que em muitos casos é difícil, senão impossível de conhecer. E justamente porque trocar palavras é política, comentar sobre o que está acontecendo, sobre as razões e os motivos alheios não é a tentativa de descrever a realidade de uma maneira isenta; ao contrário, interpretar, "descobrir" e "espalhar" as intenções alheias também é fazer política (como no "aforismo" de Tancredo Neves). Em resumo, poderíamos sintetizar a relação entre a troca do segredo e das palavras na aporia: se no segredo é que estão as razões e, como eles dizem, o "poder", na troca das palavras é que está a política.

Isso nos coloca diante da seguinte dificuldade: não é possível descrever o que esconde o silêncio no circuito fechado de circulação das palavras. Há palavras que não são para nós ouvirmos. Sobra ao antropólogo registrar a troca das palavras naquilo que ela tem de mais acessível. Como resultado, o mais importante e fundamental para os participantes desse mundo está além das nossas possibilidades objetivas de coleta de dados. A dificuldade só encontra solução no plano do método. A alternativa que encontrei está, em certo sentido, presente nestas considerações preliminares. Elas nos levam à afirmação factual de que em política, seja na linguagem regimental, seja na linguagem dos bastidores, as palavras têm usos, são instrumentos, ferramentas (na antropologia, a constatação já se encontra em Malinowski 1930).

A narrativa abaixo (propositalmente evito o termo "descrição") é o resultado do princípio, retirado de Wittgenstein, a saber: o significado de uma palavra é o seu uso em um "jogo de linguagem", quer dizer, na 
linguagem e nas práticas humanas concretas, cotidianas, com as quais ela está entrelaçada. Dessa perspectiva, o uso das palavras está submetido a regras, e dominar uma linguagem é semelhante a dominar uma técnica (Wittgenstein 1995: parágrafos 7, 11, 22, 23, 43, 150, 206, 219 etc.; Winch 1958:30-32). Se a constatação de que as palavras têm um uso é banal, a idéia de que o significado é equivalente ao uso não o é. Ela subverte a relação tradicional entre a função representacional da linguagem (tomada como o aspecto fundante, conseqüente, primeiro) e o emprego da linguagem em contextos concretos (entendido como derivado, conseqüencial, segundo) (Saussure 1995). Isso, por sua vez, vai nos forçar a adotar novas formas de descrição etnográfica e a rever os conceitos a partir dos quais, cotidianamente, percebemos o fenômeno.

\section{Um exemplo etnográfico}

Os eventos abaixo fazem parte daquilo que, em termos mais amplos (e portanto inapropriados), poderíamos chamar de "negociação" ${ }^{3}$ do Plano de Cargos e Salários dos Funcionários do Congresso Nacional. O Congresso é dividido em categorias de funcionários que nem sempre têm uma relação amistosa. Muito pelo contrário. Entre as categorias, há uma longa história de conflitos latentes que, por vezes, tornam-se explícitos e públicos. Além disso, dependendo das circunstâncias, algumas delas tornam-se mais importantes em função da proximidade dos políticos (caso, no Senado, dos chefes de gabinete que, ao contrário da Câmara, são funcionários da "Casa"), ou pelo conhecimento dos mecanismos legais-burocráticos (caso dos consultores legislativos na Câmara e no Senado), ou ainda por outras razões. Acordos tinham de ser fechados com categorias específicas (como as apontadas acima), porque uma delas poderia pôr tudo a perder (não haveria plano sem apoio dos parlamentares, como não haveria plano se não fosse, de alguma maneira, viabilizado legalmente). Para complicar, o acordo com uma categoria dependia da maneira como ela avaliava os acordos das outras, seja pela percepção das posições relativas (percepção que pode variar conforme a situação, a categoria e o contexto), seja pelos preconceitos, seja por outros motivos. Às tentativas mal-sucedidas seguiram-se longas conversas, reuniões, assembléias intermináveis e muitos outros ingredientes. Nessa "negociação", entre outros, dois "argumentos" mereceram destaque: o reenquadramento dos servidores em outras categorias (caso das categorias mais baixas) e o aumento do valor de algumas rubricas (o salário de um servidor é dividido em várias rubricas diferentes, apenas uma delas é cha- 
mada "salário"). O plano foi aprovado pela resolução n ${ }^{\circ} 07$ de 4 de abril de 2002 do Senado Federal e foi confirmado pela lei 10.863 de 29 de abril de $2004^{4}$. Na Câmara, o plano havia sido aprovado pela resolução n ${ }^{\circ} 28$ de 1998, mas foi "reorganizado" pelo Ato da Mesa n ${ }^{\circ} 110$ de 21 de março de 2002. E isso era apenas parte da história.

Para a percepção dos envolvidos (o que inclui também os funcionários), não bastava agradar todas as categorias, convencer os membros da Mesa e os parlamentares. Escrever uma resolução e implantar o plano estão, na prática, muito distantes um do outro. Implantar o plano significava comprometer verbas públicas controladas pelo Executivo. O problema é que a verba, nesse mundo, não é apenas uma quantidade econômica, mas sobretudo uma qualidade política. Além disso, a verba alocada para o plano estaria comprometida pelos próximos anos, quer dizer, para além da discricionariedade dos outros agentes públicos (não se pode gastar a verba do pagamento de pessoal para construir uma ponte, por exemplo). Mais do que isso, o movimento das instituições públicas está sempre vinculado à ação de várias pessoas ocupando cargos os mais variados - às vezes, posições que, do ponto de vista do "caminho" institucional da decisão ou da sua implementação, pareceriam "marginais". Nos termos de Elias (2001), a implementação do Plano punha em movimento um sistema de dependências recíprocas - dependências que não são formadas pelas intencionalidades dos indivíduos, mas pertencem à configuração criada pelas relações entre essas diversas posições.

A minha narrativa concentra-se em três momentos dessa longa história. O primeiro começa na reunião entre o ministro do Planejamento, Martus Tavares, com os presidentes da Câmara, Aécio Neves (PSDB-MG), e do Senado, Rames Tebet (PMDB-MG), para tratar do Plano de Cargos e Salários. Não sei sobre o que eles conversaram. O fato que pude registrar foi o comentário dos funcionários da Câmara a respeito da reunião, comentário que enfatizava o seguinte diálogo: "Estou muito irritado. Não agüento mais ouvir falar do assunto. É o possível", teria dito o ministro.

O presidente do Senado, afirmaram com um toque de ironia, gaguejou e o da Câmara teria retrucado: "É lei. O governo tem de cumprir. É sua obrigação".

Claro, não é possível ter certeza se o diálogo realmente aconteceu ou se foi exatamente assim. Faz parte do jogo, em um caso como esse, espalhar a sua versão, versão que tenha um uso qualquer (dizer que alguém é poderoso ou influente, mostrar uma diferença política, contar uma história que beneficie alguém, espalhar um boato etc.). De todo jeito, não importa para o nosso argumento se o diálogo corresponde exatamente ao que se falou na 
reunião; o nosso interesse está na seguinte questão: por que motivo ele movimentou a imaginação e o comentário de funcionários e políticos?

É preciso considerar, em primeiro lugar, que o diálogo foi percebido, interpretado (pelos funcionários, pelo menos) como um sinal claro e inequívoco de apoio ao plano pelo presidente da Câmara, um apoio de instituição, portanto; em segundo lugar, que o plano de cargos e salários atingiria a totalidade dos funcionários das duas Casas (à exceção dos funcionários dos gabinetes dos deputados, como veremos a seguir). É possível entender que essas duas considerações valham por uma explicação: intuitivamente não é difícil conceber que um plano que beneficie tanta gente seja objeto de intensos comentários e que alguém na posição de funcionário preferisse perceber nas palavras do presidente da Câmara o sinal de que ele seria de fato implementado. Entender os comentários acima como uma explicação não nos é suficiente contudo. O problema é que eles se colocam em um plano analítico que enfatiza os interesses dos agentes e que, por isso, não problematiza o papel desempenhado pela linguagem, isto é, pelo uso das palavras e suas regras. Da perspectiva de uma sociologia da linguagem, percebe-se que, em um mundo onde tudo muda o tempo todo, onde as palavras de hoje podem ser outras daqui a pouco, onde o cumprimento de uma promessa depende de como caminham as circunstâncias e as palavras alheias, as palavras dele, Aécio Neves, assumiam o papel contrário (pelo menos em aparência): estabeleciam a regra, organizavam, decidiam. Vê-se assim que o fato de o outro presidente ter gaguejado não é apenas algo prosaico ou folclórico, mas é parte indissociável da história; gaguejar representa o dilema político na sua mais dramática versão: a possibilidade de não se ter palavras quando elas são mais necessárias.

Para conseguir tal efeito, o truque do presidente da Câmara foi, na realidade, muito simples: trazer para os bastidores a linguagem utilizada geralmente em um outro contexto. Ele, de propósito, "confundiu", violou as regras desses diferentes jogos de linguagem; o resultado foi a impressão de que a ordem "natural" das coisas ("natural" da perspectiva dos políticos) tivesse se invertido, como se naquele momento fosse a lei que determinasse os bastidores e não o contrário. Há, claro, três senões: primeiro, o truque não teria o mesmo efeito se fosse de um outro qualquer; há palavras que só alguns podem dizer e inversamente, para continuar a exercer determinado papel, é preciso ser capaz de dizer certas palavras no momento oportuno. Segundo, talvez não tivesse sido tão eficaz em um outro contexto (naquele em particular tratava-se também de um conflito institucional: o Executivo pressionando para dar o mínimo possível e o Legislativo exigindo o reconhecimento da sua autonomia naquela questão). Terceiro, a atenção de to- 
dos voltava-se para o plano. Com outros personagens, circunstâncias e atenções, as mesmas palavras poderiam ser percebidas como um sinal de ignorância das regras do jogo, como motivo de piada. Nada disso significa, no entanto, que o plano tivesse sido implementado por causa desse diálogo. Mas o presidente da Câmara saiu fortalecido daquele episódio, algo que poderia ser atestado pelo seguinte comentário que circulou pelos bastidores, repetido por funcionários e políticos: "O presidente 'ganhou' do ministro".

E aqui é preciso ter um certo cuidado com a maneira pela qual vamos entender expressões como esta. É verdade que, da perspectiva dos participantes desse mundo, elas são percebidas a partir do conceito de "poder" (discussão à qual voltaremos adiante neste mesmo texto). Nossa narrativa segue outro rumo, porém. Para além do julgamento que a afirmação acima parece incorporar, estamos interessados principalmente no seu uso. E, dessa perspectiva, repetir a história não significava apenas descrever "algo que aconteceu". Pelo contrário. Passá-la adiante significava aliar-se ao presidente da Câmara, enfraquecer o ministro ou afirmar a irrelevância do presidente do Senado, ou tudo isso ao mesmo tempo - apenas para citar as possibilidades mais evidentes. Em outros contextos ainda mais específicos, que talvez não tivessem direta relação com a implementação do plano, essa história poderia ter lá diferentes usos. Repetir a história era, em suma, dar-lhe outras serventias.

O segundo momento da narrativa está ligado a uma série de reportagens, particularmente da Folha de S. Paulo, publicadas a partir de meados de junho de 2001 (Sucursal de Brasília 2001b; Vaz 2001a, 2001b; Vaz e VilaNova 2001; Vila-Nova 2001). O assunto não era novo: as contratações que os deputados faziam para os seus gabinetes. Em 2001, os deputados elegeram uma nova composição da Mesa diretora (como determina o Regimento Interno), e uma das promessas de campanha foi o aumento das verbas de gabinete. Em abril, a Folha de S. Paulo anunciou que o primeiro-secretário da Câmara (cargo que cuida da administração da Casa), Severino Cavalcanti (então no PPB-PE), encaminhava a proposta do aumento (Sucursal de Brasília 2001a), que foi aprovada em maio (Sucursal de Brasília 2001c, 2001d). O aumento não permitia contratar mais funcionários, caso a cota de 30 funcionários de cada gabinete já estivesse preenchida, mas melhorarlhes o salário. Os funcionários dos gabinetes são remunerados segundo uma lista de categorias; o aumento permitia reenquadrar funcionários e, à discricionariedade do deputado, dobrar o salário da categoria a qual o funcionário pertencesse. Mas, como sempre, o diabo está nos detalhes.

O motivo da confusão foi a qualidade das informações da reportagem: a Folha publicou o nome dos funcionários, os aumentos e os gabinetes aos 
quais eles pertenciam. A situação ficou constrangedora: salários passando de $R$ \$ 300 para $R$ \$ 5.000, contratações cruzadas (dois deputados contrataram cada um a mulher do outro), contratação de parentes etc. Uma das reportagens anunciava que o Sindicato dos Servidores do Legislativo (Sindilegis) "tem indícios graves de que esses aumentos a servidores estão, na verdade, engordando o orçamento pessoal dos parlamentares" (Nascimento apud Vaz e Vila-Nova 2001:A4) e que um servidor teria dito ao Sindicato que "dá todo o salário ao deputado e fica só com o vale-alimentação e as horas extras além das 19hs" (Vaz e Vila-Nova 2001:A4). Mas quem havia fornecido as informações à imprensa? Aqui a história começa a ficar interessante.

O imbroglio foi o resultado do sucesso da atuação do então presidente do Sindilegis, Ezequiel Nascimento, na aprovação do plano de cargos e salários - por mais paradoxal que isso possa parecer. De uma maneira geral, os funcionários das diversas categorias creditavam-lhe o sucesso da negociação. E aqui, novamente, precisamos dos detalhes. O Sindicato reúne todos os funcionários da ativa e os aposentados do Senado, da Câmara e do Tribunal de Contas da União. Na Câmara, há três tipos de funcionários, segundo o seu vínculo empregatício: os estatutários (concursados), os Cargos de Natureza Especial (CNEs, cargos de confiança) e os assessores parlamentares. Os dois primeiros estão submetidos à lei 8.112/90 que regula o funcionalismo público federal. Os assessores parlamentares, não. O problema é que, antes da Constituição de 1988, os assessores eram contratados pelas regras da Consolidação das Leis do Trabalho (CLT), mas depois da Constituição e da lei 8.112/ 90, isso já não era possível. Como conseqüência, estes últimos não estão sob o abrigo de nenhum regime trabalhista; eles podem, por exemplo, ser demitidos a qualquer hora, sem qualquer justificativa, e não são desconhecidos casos de demissão de funcionárias grávidas (Painel 2001).

Seja como for, as categorias dos assessores parlamentares (segundo as quais eles são remunerados) estão vinculadas à rubrica "salário" dos funcionários estatutários, e o Plano de Cargos e Salários não alterava essa rubrica em particular. Em resumo, os assessores parlamentares, ao contrário dos servidores estatutários e dos CNEs, não seriam beneficiados pelo plano, embora também fossem associados ao Sindilegis e representassem expressiva força eleitoral. As reportagens foram, portanto, a tentativa do Sindicato de mexer nessa situação em prol dos assessores. Em duas ocasiões, quase com a mesma expressão, lê-se: "para o presidente do Sindilegis, as distorções dos reajustes e contratações nos gabinetes decorrem da precariedade do vínculo empregatício desses servidores" (Vaz 2001a:A8; Vaz e Vila-Nova 2001:A4). Nem tudo saiu, porém, como o planejado. Há nas palavras, no discurso, "poderes e perigos que mal se imaginam" (Foucault 1996:8). 
Óbvio, as informações só poderiam ter saído da administração da Câmara. E o problema está, uma vez mais, nos detalhes. Em fins de maio e começos de junho, o então presidente da Câmara exonerou o diretor geral, Ademar Sabino, que havia exercido o cargo durante 18 anos com mãos de ferro, dizem. Um diretor que, pelas histórias que circulavam, saberia até mesmo dos pequenos comentários ditos ao acaso a seu respeito. O novo diretor geral, Sérgio Sampaio, tinha recém tomado posse quando a primeira matéria foi publicada. Resultado: uma informação importante e sigilosa tinha "vazado" para a imprensa, no momento em que a nova administração ainda estava nos seus primeiros passos. E o comentário que se seguiu foi o seguinte: "Como foi parar nas primeiras páginas? Na época do outro isso não acontecia".

Como no momento anterior da presente narrativa, esta não foi apenas uma pergunta curiosa, mas sobretudo uma posição política. Seu uso mais evidente era o de criticar o presidente da Câmara. E aqui é preciso fazer algumas considerações. O papel do presidente não é somente pôr assuntos em votação ou decidir questões de ordem. A importância da presidência da Casa está vinculada à sua contribuição para a "construção da maioria" que, no Plenário, aprova ou derruba as proposições submetidas a voto. Isso tem, é claro, relação com as possibilidades institucionais do cargo de presidente, quer dizer, com as prerrogativas que lhe confere o regimento interno. Há aqui, contudo, um detalhe. $\mathrm{O}$ presidente nem sempre consegue fazer valer a sua vontade ou a sua decisão sobre uma interpretação do regimento, a administração ou o processo legislativo. Suas decisões podem ser objeto de recurso - ainda mais em se tratando de assuntos polêmicos. Para mantê-las, é necessário o apoio da maioria no Plenário, pois é ela quem, em última instância, decide: assim é o regimento. Este é o paradoxo da situação: se o presidente pode, para poder ele depende.

Com a publicação da reportagem, a impressão era a de que a situação tinha fugido ao controle. Se o presidente não era capaz sequer de pôr ordem na administração da Casa, como ele conseguiria ajudar a construir maiorias? Como suas palavras poderiam estabelecer a regra, organizar as trocas, decidir? Some-se a isso o fato de que o então presidente tinha, segundo se dizia pelos bastidores, ambições políticas para vôos mais altos (tanto que - a história prossegue - ele seria eleito governador de Minas Gerais em 2002, mas já no começo do mesmo ano falava-se de uma possível candidatura à Presidência da República). Muita coisa parecia estar em jogo naquela situação. E aqui começa o terceiro "momento" da nossa história. O presidente foi atrás da burocracia para saber quem havia fornecido as informações à imprensa. Na burocracia, ninguém disse: "Fui eu". Quem o disse foi o presidente do Sindilegis: "Diga-lhe que fui eu". 
Assumir a responsabilidade de um fato como esse não é banal. Para proteger o(s) funcionário(s) da Casa, o presidente do Sindicato teve de sustentar uma posição. Mas isso, por sua vez, trouxe novos desdobramentos. Se o autor da elocução é identificado (o que nem sempre é possível de maneira tão explícita), há um adversário para combater, alguém a quem dirigir as conseqüências, conseqüências que podem variar conforme as estratégias, as forças e os contextos. Tanto pode servir para continuar o conflito, como para abrir um ciclo de trocas. Freqüentemente ambos. De todo jeito, a "resposta" (segundo a percepção "nativa") não tardou. "O presidente da Câmara disse que não vai mais fazer o plano. Foi a matéria. Foi culpa do presidente do Sindicato", dizia-se pelos corredores.

A circulação das palavras assume aqui características semelhantes às que a etnografia já apontou para os sistemas agonísticos de trocas. O exemplo que nos serve de comparação é o do Kula. Neste último, a importância dos objetos depende da quantidade de vezes em que eles são dados e tornados a dar. Assim, quanto mais tempo um objeto qualquer circula, mais valioso ele se torna e maior "grandeza" confere a seu proprietário original - como se, ao passar por trocas sucessivas, o objeto ganhasse, por assim dizer, "quantidades" simbólicas suplementares (Abreu 1997). Com a troca sucessiva, as palavras na política também parecem ganhar quantidades "simbólicas suplementares" que aqui produzem três efeitos: (a) a sua origem perde importância; (b) o comentário ganha mais e mais a impressão da verdade, de algo que "todos sabem"; (c) as palavras vão se modificando como se ao entrarem nesse circuito aberto, elas adquirissem uma materialidade toda própria, materialidade que, em um outro plano, representa a autonomia da palavra em face da sua referencialidade, quer dizer, da relação entre significante e significado. Metaforicamente, é como um burburinho que se espalha pelos corredores da Casa e que vai se transformando cada vez que avança; quando é inteiramente percebido, o murmúrio já mudou a paisagem em que todos vivem, o horizonte em que a ação faz sentido. É o mundo do boato, das informações anônimas — o "centro de criatividade" ao qual se referia Tancredo Neves.

A diferença talvez resida no fato de que, no caso do Kula, é preciso guardar a lembrança do caminho que o objeto percorreu. É possível aventar a hipótese de que no circuito fechado de circulação de palavras aconteça, em alguns casos, algo semelhante, na medida em que é preciso guardar a lembrança de quem disse o quê — hipótese impossível, no atual estágio das pesquisas, de submeter ao teste etnográfico. No circuito aberto de circulação das palavras, ao contrário, essa memória é irrelevante na maior parte dos casos; importante mesmo é a credibilidade do comentário, credibilidade 
que, no mais das vezes, se dissocia da sua origem e se apega à sua troca sucessiva, à sua repetição como fonte de autoridade.

A informação que consegui coletar — se é que a ela se pode dar crédito - foi a de que o comentário se originou no gabinete do presidente da Câmara (o que seria, aliás, provável), vindo particularmente do chefe de gabinete (o que é impossível se saber com certeza). Mas isso realmente não importa, porque naquele momento - independente de quem primeiro espalhou a história - o presidente do Sindicato tinha à sua frente uma situação similar àquela que, pouco antes, havia enfrentado o presidente da Câmara: a sua continuidade como ator político relevante parecia ameaçada. Um presidente de sindicato que inviabiliza o aumento da sua categoria não parece ser um político de muito futuro. E o uso do comentário pelos funcionários significava, como em todos os outros casos acima, assumir uma posição política: criticar a atuação dos seus dirigentes. É preciso contar também com a velocidade com a qual um determinado boato se espalha, principalmente um que atinja o bolso de tanta gente. Não demorou muito para os telefones do Sindicato e do seu presidente começarem a tocar. As possíveis conseqüências da situação eram, para alguém treinado nos rumos desse mundo, imediatamente "visíveis". O presidente do Sindilegis dirigiu-se a um secretário da Mesa e a um líder. "Se o presidente da Câmara não fizer, publico essa outra matéria. Não tenho nada a perder".

Em uma situação como aquela, a procura de interlocutores específicos (provavelmente aqueles com quem se tem maior intimidade ou com os quais se acredita ter maior possibilidade de "sucesso") pôs em movimento o sistema fechado de circulação de palavras que, ao contrário do outro, é nomeado e personalizado. Certas coisas não são ditas diretamente. É preciso utilizar intermediários, e estes, por sua vez, podem ter de procurar outros intermediários. Essas redes variam de contexto para contexto, mas há sempre, mesmo que fruto das circunstâncias, uma precedência a ser respeitada e ela é a face mais visível de um sistema de dominação que já tivemos oportunidade de vislumbrar ao discutirmos o papel do líder. Não temos espaço aqui para examinar o assunto como ele mereceria.

Daquilo que interessa mais de perto ao nosso exemplo é preciso notar que esse sistema de dominação possui características semelhantes àquelas que Bourdieu (1980) já examinou alhures: um sistema que, em certo sentido e em alguns momentos, nega a si próprio enquanto dominação; por exemplo, na pessoalidade aparentemente "desinteressada" que incorpora a expectativa futura de retribuição, e com ela a aliança política e muitas vezes a subordinação. Desta perspectiva, o papel do mundo do segredo, do circuito fechado de circulação das palavras, parece bem claro como diria Foucault: 
[...] em toda sociedade a produção do discurso é ao mesmo tempo controlada, selecionada, organizada e redistribuída por um certo número de procedimentos que têm por função conjurar seus poderes e perigos, dominar seu acontecimento aleatório, esquivar sua pesada e temível materialidade (Foucault 1996:9).

A proposição de Foucault cabe perfeitamente no nosso exemplo: era preciso colocar as palavras de volta aos seus lugares, recuperar a sua instituição. Depois que o outro político falou com o secretário e o líder, não sei exatamente o que aconteceu, quem falou com quem, quem disse o quê; ao mesmo tempo, os comentários pelos corredores intensificaram-se. No final daquele mesmo dia, o presidente avisou: "Vou implantar, sim, o plano". E ele nunca havia dito que não o faria. A confusão tinha sido o resultado de um mal-entendido. O presidente da Câmara e o presidente do Sindicato encontraram-se no dia seguinte - só estavam presentes os dois - e este último saiu dizendo: "Somos os mais novos velhos amigos de infância. O presidente me disse que, de agora em diante, falaremos diretamente, sem intermediários". E o comentário geral foi: "O presidente do Sindilegis enfrentou e ganhou do presidente da Câmara". Mas isso não significa que privadamente ele se sinta vencedor. Pode até acontecer que, com alguém mais íntimo, ele comente: "Fui preparado para a guerra, e ele me tratou como se fôssemos velhos amigos. Aquilo me desarmou".

Novamente, como em todos os momentos anteriores desta narrativa, é preciso examinar o uso das palavras e as suas implicações. De uma perspectiva mais geral - e, portanto, mais abstrata - tratar o caso como um malentendido equivale a afirmar que os outros fizeram um mau uso das palavras e que as palavras alheias não tinham conteúdo ou referencialidade. Em um plano mais específico, as conseqüências dessa "afirmação" estão relacionadas à maneira como se lida com a assimetria na política brasileira. Tudo se passa como se aceitar uma provocação, reconhecer pública e explicitamente um conflito significasse dar ao outro o status de um igual - algo que interessa àquele que está no plano inferior e deve ser evitado por aquele que está em uma posição superior. Daí percebe-se toda uma série de usos e estratégias adotados por este último: a necessidade de falar por meio de intermediários (isso significa dar ao outro um status menor), o uso de circunlóquios e fórmulas metafóricas e a negação de que tais ou quais palavras signifiquem uma crítica ou um conflito . "Evidente" desde o princípio (do ponto de vista dos participantes dessa história) era o fato de que esses dois agentes — o presidente da Câmara e o presidente do Sindicato - não estavam no mesmo plano; havia entre eles uma precedência institucional que, por conta de toda a confusão, parecia, em certo sentido, "enfraquecida". 
Assim, quando o presidente da Câmara diz que tudo não passou de uma confusão - e, com isso, afirma que os outros fizeram um mau uso das palavras - ele está recusando o próprio conflito e a confusão entre as respectivas posições. A atitude adotada permitiu a solução do impasse através de um ato de relação, pela linguagem da pessoalidade, da troca de gentilezas, de amabilidades e (o que é um pouco diferente) de cordialidades próprias da nossa sociabilidade (vide Da Matta 1997; Buarque de Holanda 2002; e para uma etnografia que enfatiza a importância da pessoalidade na política no Congresso Nacional, Bezerra 1999). Justamente por causa da assimetria, a ação do presidente da Câmara - a gentileza e cordialidade por ele demonstradas e a promessa de que, dali por diante, esta seria a forma de tratamento adotada - por si só já significava uma prestação. Ao presidente do Sindicato, restavam poucas alternativas: continuar o conflito naquelas circunstâncias era um mau negócio; resolvê-lo, implicava em aceitar a assimetria e a precedência - reconhecimento nunca expresso enquanto tal, mas que já estava contido, por exemplo, na percepção de que a afirmação: "agora somos os mais novos amigos de infância", fosse algo que merecesse divulgação. Seja como for, com a precedência reinstaurada, o presidente da Câmara tomava novamente para si a enunciação da ordem: uma vez mais suas palavras organizavam, decidiam, ao menos momentaneamente, é claro.

A outra reportagem foi, de fato, publicada algum tempo depois, mas sem os detalhes (daquela vez o diabo tinha ficado preso na caixa). Depois de algum tempo, perguntei como ia o plano. "Não tinha jeito, eles tinham de fazer", foi o que me disseram.

\section{A desconfiança das palavras}

Mas qual seria em um contexto como esse a "natureza" das palavras, da linguagem? A melhor forma de abordar o problema talvez seja a partir da maneira como os participantes desse mundo a percebem. Nesse sentido, o caminho mais seguro é basear-me uma vez mais na etnografia, no conselho que um repórter - bem conhecido, ganhador de vários prêmios - me deu, conselho que ele percebia como um favor, mais precisamente uma contraprestação. Nele, o repórter expressava o que, segundo sua experiência, era a atitude que me garantiria uma "boa" inserção nesse meio, o lembrete que deveria me acompanhar em todos os momentos: "Tenha sempre em mente a sua própria inocência", ele disse. A frase continha duas advertências, explicou-me: (a) está sempre acontecendo mais do que se sabe; (b) as pessoas 
têm intenções que se desconhecem. E completou: "Todos nós somos, em alguma medida, inocentes". — E você? "Eu também".

O depoimento acima expressa a experiência que não é apenas a de repórter, mas que representa uma certa "sabedoria" da política, vinda de um fazer: desconfie, desconfie sempre. A desconfiança rebate, no plano da experiência, a contradição resultante das condições objetivas desse meio social (utilizando o conceito de Marx com certa liberalidade): a necessidade de conhecer e a impossibilidade da certeza, já que a certeza se encontra atrás do segredo, naquilo que não se conhece. Ao político só resta falar, mas como o comentário não consegue resolver a contradição resta-lhe apenas uma única solução: reelaborar continuamente, no plano do discurso, a contradição objetiva na qual vive. O político está correto na sua sociologia intuitiva: falar de política é fazer política, e a verdade não é o fazer mais importante.

O fato etnográfico: a realidade na qual o político tem de agir é construída por aquilo que faz sentido em um determinado contexto - essa é a realidade que lhe interessa, a concretude que lhe serve, aquilo que se diz, é. Isso me lembra Dom Quixote ou, mais precisamente, a descrição de Foucault a quem podemos, com certa liberalidade, parafrasear: "[entre] a primeira e a segunda parte do romance [entre o primeiro livro que descreve as desventuras de Dom Quixote e o segundo no qual as pessoas que leram o primeiro livro o reconhecem como o herói daquelas aventuras], no interstício desses dois volumes e somente pelo poder deles", assim como o nosso político, por assim dizer, em uma outra "literatura",

Dom Quixote assumiu a sua realidade. Realidade que ele deve somente à linguagem e que permanece totalmente interior às palavras. A verdade [de Dom Quixote e daqueles que vivem no mundo da política e a partir de suas regras] não está na relação das palavras com o mundo, mas nessa tênue e constante relação que as marcas verbais tecem de si para si mesmas (Foucault 1985:63).

Em um outro plano, porém, a distância entre as palavras e as coisas que o universo da política instaura, que os sujeitos vivem como desconfiança e como um agir, reflete uma epistemologia e uma Weltanshauung próprias da nossa política ${ }^{7}$. Aqui, as palavras não descrevem a realidade, mas a escondem, isto é, o seu parentesco com as coisas não deve ser levado muito a sério; além disso, as pessoas são insinceras, e suas palavras não representam o que elas pretendem, pensam ou sentem. Por fim, a relação com o discurso alheio é tortuosa, na medida em que o discurso engana, mas ao mesmo tempo dá pistas sobre o que esconde. Nessa "separação ontogênica" 
entre as palavras e as coisas que a política celebra, a perspectiva sociológica inverte as máximas da experiência dos sujeitos: não é porque existe o segredo que se desconfia, mas se desconfia porque essa é, por assim dizer, a "natureza" da linguagem; se o segredo não existisse seria preciso inventá-lo.

\section{O poder e a troca}

Estranho o percurso: abordamos o universo político tendo como ponto inicial a linguagem, chegamos porém ao poder e à troca. Com efeito, se a preeminência da troca foi, por assim dizer, mais "evidente", é preciso reparar que nunca estivemos longe do poder: a maioria dos fenômenos apontados acima é compreendida no campo político a partir do conceito de poder. A questão que surge daí é a seguinte: qual a relação entre poder e troca (se é que há alguma)? Novamente, o ponto de partida da nossa investigação é a maneira pela qual eles são percebidos pelos participantes desse mundo. E o fato etnográfico é o desequilíbrio e a assimetria a partir dos quais um e outro são tratados. Por um lado, o poder é a categoria que permite aos políticos refletir sobre sua experiência. Eles chegam, inclusive, a reduzir uma a outra: "Política é a luta pelo poder", eles dizem.

Horas sem fim são gastas na tentativa de desvendar a natureza dessa misteriosa entidade, como se a "essência" do poder fosse o segredo capaz de abrir as portas para o paraíso das ambições realizadas e que, uma vez desvelado, descoberto, desnudo pudesse ser apropriado, dominado, instrumentalizado. A troca, por outro lado, não gera grandes dúvidas, nem parece levantar maiores questões metafísicas. Ela é óbvia e, ao contrário do que acontece no caso do poder, a reflexão sobre a troca não é um exercício ao qual se dediquem os participantes desse mundo. Isso não deixa de ser curioso se a troca exerce, como defendo, um papel central nessa atividade.

A assimetria repete-se na maneira pela qual o poder e a troca são pensados na literatura. $\mathrm{O}$ caso do poder não precisa de grandes exemplos: o seu uso enquanto categoria central do político se dá em diversos ramos das ciências sociais e humanas. Com isso não quero dizer que os acadêmicos e os participantes da política tenham em relação ao conceito de poder a mesma atitude, mas ambos o elegem para elaborar o significado da dimensão política. Já a troca é percebida de outra maneira. Quando se fala dela na política, geralmente o discurso assume o caráter de uma condenação moral; em parte, porque a troca é englobada por outros conceitos, como o "coronelismo" e seu irmão gêmeo, o "clientelismo". A partir deles, ela é percebida como a herança de um passado longínquo, arcaísmo destinado pela evolução social a 
desaparecer - vaticínio que contém doses desiguais de esperança, ideologia e análise acadêmica. Curiosamente, neste aspecto, a literatura, isto é, parte dela, nada mais faz do que repetir com maior sofisticação a mesma condenação do senso comum ao, como se diz, "toma lá, dá cá" ou à "lei de São Francisco: é dando que se recebe". A conseqüência disto é que, ao mesmo tempo em que se aponta a centralidade da troca, esconde-se a sua real dimensão.

Outras vezes, as interpretações que colocam a troca no centro dos acontecimentos são criticadas por darem à realidade um conteúdo conservador que enfatizaria a idéia de "ordem", em detrimento da "natureza" potencialmente conflitante e caótica da política. A crítica é poderosa e está correta na sua intuição mais fundamental. Ela possuiria, contudo, um erro de princípio, se aplicada a este trabalho. A troca aqui não é uma ferramenta que utilizo para explicar a política, mas sim uma categoria "nativa". Se há uma ênfase na ordem (e eu acredito que ela exista de fato), ela não é o resultado não intencional dos meus instrumentos analíticos, mas talvez uma necessidade objetiva deste meio social (hipótese que, por evidente, mereceria maiores detalhamentos do que aqueles que podem ser desenvolvidos aqui). A constatação não é nova. Embora não se refira especificamente à troca, Moore (1983:50) já chamava a atenção para a existência de processos a partir dos quais as pessoas procuram "controlar sua situação, lutando contra a indeterminação", quer dizer, a tentativa de fixar a realidade social, de dar-lhe predicabilidade.

De todo jeito, a etnografia leva-nos a rever a percepção enunciada acima. Da perspectiva dos nossos dados, o significado de "poder" não é a definição do seu "ser em si", da sua "essência", mas o registro etnográfico dos seus vários usos e das regras que o governam. Dessa perspectiva, "poder" é utilizado em vários contextos diferentes, em cada um deles segundo regras diversas, de forma que a pergunta "o que é poder?" tem tantas respostas quantos os contextos nos quais o conceito é empregado. Assim, o burocrata dirá que tem poder quem libera a verba, mas às vezes é quem "manda" ou quem pode sair mais cedo ou chegar mais tarde. Os políticos podem definilo de maneiras diferentes, como a capacidade de transformar a realidade naquilo que você habitualmente nem imagina possível, isto é, como o exercício de uma vontade soberana capaz de submeter a tudo e a todos ou, ainda, como a influência que um dos agentes tem sobre os outros. Em alguns casos, o poder simplesmente quer dizer visibilidade ou a diferença qualitativa em relação àqueles que o cercam. Em certos contextos, significa a capacidade de representar o todo, incorporar esse papel em face de diferentes agentes; em outros, que o mundo gira ao seu redor. Às vezes, tem poder 
aquele que fala; às vezes, quem fica em silêncio; em outras, é o "dono" da idéia, o "dono do partido" ou "o dono daquela vaga de deputado". Repórteres têm poder, e a negociação com os políticos pode ser entendida como uma relação entre poderes. Nessas e em outras situações não encontramos nenhuma substância comum em função da qual pudéssemos dizer: "isto é, enfim, o poder".

Inegavelmente, tais situações estão ligadas a uma rede de semelhanças que, em certas circunstâncias, se cruzam, em outras, se justapõem, ora com semelhanças de detalhe, ora com semelhanças centrais (vide Wittgenstein 1995: parágrafos 65 a 67). Com isso não quero dizer que não existam relações de mando e obediência, força, violência, brutalidade (às vezes dissimuladas pelas palavras "generosas"), conquista de territórios ou derrota dos inimigos. Digo simplesmente que a categoria de poder talvez não seja a melhor maneira de perceber a concretude destes e de outros fenômenos aparentados.

A troca, por sua vez, é um fazer imediatamente vinculado à experiência social. Seu papel é pôr em movimento, em um mesmo sistema, coisas e pessoas que, a princípio, não poderiam por si mesmas ter nenhuma relação. Em um certo sentido, portanto, ela viola os limites empíricos das coisas singulares, quer dizer, permite que as coisas tenham usos que não cabem nas circunstâncias para as quais elas originalmente se destinavam ${ }^{8}$. Como resultado, a troca não pode ser redutível àquilo que circula ou às pessoas que trocam: defini-la é enganar-se profundamente a respeito do seu papel. A pergunta "o que é a troca?" não faz sentido, pois equivale, neste contexto, a dizer: "eu não domino a regra, a técnica necessária para que esta realidade social faça sentido para mim".

Mas o mais importante para o meu argumento: dizer, por um lado, "o poder é isso" e, por outro, "isso é troca" representam atitudes diferentes dentro do campo político do Congresso Nacional. O primeiro caso é a tentativa de descortinar a "essência" do poder com o objetivo de possuí-lo. O segundo, ao contrário, significa afirmar que as pessoas e as coisas estão inseridas em um certo tipo de relação, ou melhor, significa colocar as pessoas e as coisas em relação. Da perspectiva de uma sociologia da linguagem, tudo se passa como se a reflexão sobre o poder pudesse superar a "separação ontogênica" enunciada acima e suprir a palavra com um conteúdo no mundo, associar as palavras e as coisas, instaurar a referencialidade. A troca, por outro lado, tem o papel oposto: ela dissocia as palavras e as coisas, na medida em que lhes são dadas outras serventias, diferentes usos que variam conforme as circunstâncias. Dessa forma, a troca coloca palavras, coisas e pessoas em relação e, às vezes, nas relações as mais inusitadas. De qualquer forma, a opo- 
sição entre essas duas atitudes permite-nos, acredito, pensar o poder e a troca não mais a partir das suas "características intrínsecas", substantivas, mas sim da sua relação neste contexto etnográfico.

Por fim, ainda com respeito à troca, é preciso fazer alguns breves comentários sobre a maneira como - até onde fui capaz de elaborar - a etnografia acima "dialoga" com a teoria antropológica. O ponto central parece-me o seguinte: a política no Congresso Nacional brasileiro inverte a relação, digamos, "tradicional" entre a precedência e a troca. Nas sociedades tradicionais, segundo a etnografia, a regra que organiza a precedência antecede o ato da troca, seja ela preferencial ou prescritiva, quer dizer, para haver troca é necessário que haja antes uma regra que estabeleça o que é valioso e deve ser trocado, com quem se deve trocar ou com quem seria preferível trocar (Abreu 1997). No Congresso brasileiro, ao contrário, não existe uma regra desta ordem.

Novamente, isso é o resultado das condições sociais "objetivas": o valor daquilo que circula - homens, mulheres, coisas, cargos, verbas, favores, ritos, cerimônias, palavras, informações, jantares, recepções, conselhos, serviços, demonstrações de afeto etc. — depende das contingências, do acaso, das condições objetivas imaginadas e até mesmo idealizadas de cada situação. Não há uma regra que estabeleça o que é valioso trocar e com quem se deve ou se é preferível trocar, e sim o inverso: o momento, o cálculo (equivocado ou não), as ambições e as estratégias regulam o que é importante, valioso ou mesmo essencial e com quem seria melhor trocar. A precedência varia conforme o contexto político, portanto, não é a regra da precedência que organiza a troca, mas são as trocas, percebidas em um determinado contexto como "necessárias", que estabelecem a precedência. Esta, enfim, parece ser a peculiaridade deste sistema diante daqueles tradicionalmente descritos pelos antropólogos: a palavra é um elemento da troca — possibilidade para a qual Lévi-Strauss já chamava a atenção, mas que nunca se preocupou em descrever etnograficamente.

Baseado em tudo isso, é possível sugerir uma fórmula, na minha opinião ainda provisória, mas que serve como uma primeira aproximação: no Congresso Nacional, em alguns contextos, as palavras organizam ou desorganizam a troca das coisas; em outros, a determinam; em outros ainda as palavras são, elas mesmas, prestações. No atual estágio das pesquisas, ainda falta desenvolver técnicas para descrever etnograficamente a palavra como uma prestação - o que, incidentalmente, explica o caráter experimental deste texto. Pelo mesmo motivo, vários dos fenômenos apontados pela etnografia da política no Congresso - e considerados "normais" não teriam lugar na antropologia clássica senão como "desvios": receber a 
prestação sem conhecer sequer a equivalência da contraprestação; não cumprir a palavra empenhada - o contexto muda - e sistemas de "troca generalizada" sem regras prescritivas ou preferenciais.

Recebido em 30 de julho de 2003

Aprovado em 30 de agosto de 2005

Luiz Eduardo Abreu é professor do Programa de Mestrado em Direito do Centro Universitário de Brasília (UniCEUB). E-mail: <luizeabreu@yahoo.com.br>

\section{Notas}

*Agradeço as valiosas sugestões de Miréya Suarez, Frederico Silva e Piero Leirner.

${ }^{1}$ Transcrição da sessão do Senado do dia 19 de novembro de 1998, grifos meus.

${ }^{2}$ Entre as normas jurídicas e os argumentos de instituição, há de forma evidente, diferenças. Mas, para o nosso assunto, elas podem ser colocadas em uma mesma categoria, na medida em que ambas se opõem à linguagem dos bastidores, como veremos a seguir.

${ }^{3}$ Talvez mais interessante fosse o termo "micronegociações" utilizado por Latour e Woolgar (1986). Em Laboratory Life, eles mostram como os "fatos" científicos são criados por uma série de micronegociações que não possuem entre si uma direção global imediatamente perceptível. Eles mostram ainda como as proposições "científicas" mudam cotidianamente, fruto do resultado imprevisível dessas negociações (vide Abreu 1994). De todo jeito, por duas razões, os termos "negociação" e mesmo "micronegociação" parecem-me insatisfatórios: (a) a importância da linguagem que, como estou sugerindo neste texto, acaba operando como um mecanismo com certa autonomia; (b) o termo encobre fenômenos que podem, etnograficamente, ser tratados separadamente.

${ }^{4}$ Normalmente, uma resolução do Senado Federal não precisa ser "confirmada" por uma lei ordinária. A idéia é que uma lei que pode ser vetada pelo Presidente da República não pode decidir sobre os assuntos internos de um outro poder. Contudo, a emenda constitucional 19 de 1998 modificou um dos incisos do artigo 52 que, segundo algumas interpretações, "dá a entender" que se precisaria de uma lei. Por via das dúvidas, votou-se a lei. 
5 "Logo que o proprietário de um kitoum [nome dado aos objetos antes de entrarem no circuito do Kula] o dá ao seu primeiro parceiro, é o nome do parceiro que 'sobe', enquanto o do primeiro proprietário 'desce'. Contudo, quanto mais o objeto é dado e tornado a dar, quanto mais ele se distancia de seu proprietário de origem, mais o nome deste 'engrandece'"' (Godelier 1996:128, versão minha para o português). Portanto, o objetivo do "jogo" não é recuperar o mais rapidamente possível um kitoum equivalente. O interesse do proprietário original é o de lançá-lo o mais longe e pelo maior tempo possível, para elevar, ampliar, magnificar o seu nome.

${ }^{6}$ A racionalização é compatível com as propriedades de sistemas ideológicos hierárquicos, quer dizer, sistemas baseados na precedência e, portanto, na relação de pertencimento; basta para tanto compará-los com os sistemas ideológicos igualitários modernos, nos quais os sujeitos são pensados como indivíduos: autônomos, iguais e livres (vide Dumont 1975:16-31; 1985:263-277).

${ }^{7}$ A especificidade desta Weltanshauung fica clara se comparada à maneira como outros grupos se relacionam com a linguagem. Seguimos aqui Crapanzano, cujo trabalho nos inspira e simultaneamente serve como parâmetro de comparação. Com efeito, Crapanzano trabalha a partir da idéia de uma axiologia, dos valores e do correspondente comprometimento dos indivíduos com uma ética presente na linguagem (Crapanzano 2000).

${ }^{8}$ Em certo sentido, a lição já está presente, acredito, na Escola Sociológica Francesa. A teoria das trocas não se baseia na conceitualização do que seja a troca, mas em um conjunto de relações que põe em movimento pessoas, bens materiais e simbólicos (vide Abreu 2001). É interessante observar a dificuldade que as categorias ocidentais têm de traçar-lhe um contorno preciso; nesse sentido, veja-se como a idéia, presente em Mauss, de que a troca mistura pessoas e coisas, por um lado, e categorias de interesse e desinteresse, por outro, tem sido trabalhada no sentido da sua impossibilidade (Derrida 1997; criticado de maneiras diferentes por Bernasconi 1997; Bourdieu 1997), como uma prática vazia (Gasché 1997), a partir da ênfase no desinteresse (p. ex. Godbout 1999). 


\section{Referências bibliográficas}

ABREU, Luiz Eduardo. 1993. A lei, o poder e a lógica: estudo antropológico do universo político de Corte de Pedra, povoado do interior da Bahia. Dissertação de mestrado, Universidade de São Paulo.

1994. "As redes e o cotidiano em Laboratory Life". Cadernos de Campo, 4:175-184.

.1997. "Um enigma deste mundo". AnuárioAntropológico, 96:239-264.

1999. Os labirintos do Minotauro - troca, política e linguagem. Tese de doutorado, Universidade de Brasília.

2001. "Wittgenstein lecture on ethics and french anthropological tradition". In: R. Haller e K. Puhl (eds.), Wittgenstein and the future of philosophy. A reassessment after 50 years. vol. 1. Kirchberg am Wechsel: Austrian Ludwig Wittgenstein Society. pp. 2935.

ARAGÃO, Luiz Tarlei de. 1990. "Mère noire, tristesse blanche". Le discours psychanalytique - revue de l'Association Freudienne, 4:47-65.

BERNASCONI, Robert. 1997. "What goes around comes around: Derrida and Levinas on the economy of the gift and the gift of genealogy". In: A. D. Schrift (ed.), The logic of the gift. Toward an ethic of generosity. London: Routledge. pp. 256-273.

BEZERRA, Marcos Otávio. 1999. Em nome das "bases". Política, favor e dependência pessoal. Rio de Janeiro: Relume Dumará/ Núcleo de Antropologia da Política. Coleção Antropologia da Política.

BOURDIEU, Pierre. 1980. "Le sens pratique". In: Le sens commun. Paris: Les Éditions de Minuit.
1997. "Marginalia-some additional notes on the gift". In: A. D. Schrift (ed.), The logic of the gift. Toward an ethic of generosity. London: Routledge. pp. 231-241.

BUARQUE DE HOLANDA, Sergio. 2002. "Raízes do Brasil", $3^{\mathrm{a}}$ ed. In: S. Santiago (ed.), Intérpretes do Brasil, vol. 3. Rio de Janeiro: Nova Aguilar. pp. 9291102.

COUTO, Ronaldo Costa. 1995. Tancredo vivo, casos e acasos. Rio de Janeiro: Record.

CRAPANZANO, Vincent. 2000. Serving the word. Literalism in America from the pulpit to the bench. New York: The New Press.

DA MATTA, Roberto. 1997. Carnavais, malandros e heróis - para uma sociologia do dilema brasileiro. $6^{\mathrm{a}}$ ed. Rio de Janeiro: Zahar Editores.

DERRIDA, Jacques. 1997. "The time of the king". In: A. D. Schrift (ed.), The logic of the gift. Toward an ethic of generosity. London: Routledge. pp.121147.

DUMONT, Louis. 1975. La civilisation indienne et nous. Paris: Librairie Armand Colin. Collection U Prisme. . 1985. O individualismo. Uma perspectiva antropológica da ideologia moderna. Rio de Janeiro: Rocco.

ELIAS, Norbert. 2001. Sociedade de corte. Investigação sobre a sociologia da realeza e da aristocracia de corte. Rio de Janeiro: Jorge Zahar Editor.

FOUCAULT, Michel. 1985. As palavras e as coisas. Uma arqueologia das ciências humanas. São Paulo: Martins Fontes.

1996. A ordem do discurso. Aula inaugural no Collège de France, pronunciada em 2 de dezembro de 1970. 
São Paulo: Edições Loyola. Leituras Filosóficas.

GASCHÉ, Rodolphe. 1997. "Heliocentric exchange". In: A. D. Schrift (ed.), The logic of the gift. Toward an ethic of generosity. London: Routledge. pp. 100-117.

GODBOUT, Jacques. 1999. O espírito da dádiva. Rio de Janeiro: Fundação Getúlio Vargas.

GODELIER, Maurice. 1996. L'énigme du don. Paris: Fayard.

LANNA, Marcos. 1995. A dívida divina. Troca e patronagem no Nordeste brasileiro. Campinas: Unicamp.

LATOUR, Bruno e WOOLGAR, Steve. 1986. Laboratory life. The construction of scientific facts. New Jersey: Princeton University Press.

LEAL, Victor Nunes. 1997. Coronelismo, enxada e voto-o município e o regime representativo no Brasil. Rio de Janeiro: Editora Nova Fronteira.

LÉVI-STRAUSS, Claude. 1968. "Introduction à l'œuvre de Marcel Mauss". In: M. Mauss (ed.), Sociologie et anthropologie. Paris: Presses Universitaires de France. pp. ix-lii.

MALINOWSKI, Bronislaw. 1930. "The problem of meaning in primitive languages". In: C. K. Odgen e I. A. Richards (eds.), The meaning of meaning. London: Keagan Paul, Trech, Trubner \& Co. Ltd.

MAUSS, Marcel. 1968. “Essai sur le don. Forme et raison de l'échange dans les sociétés archaïques". In: Sociologie et anthropologie. Paris: Presses Universitaires de France. pp. 143-279.

MOORE, Sally Falk. 1983. Law as process - an anthropological approach. London: Routledge \& Kegan Paul.

Painel 2001. 2001. "Demissão polêmica". Folha de S. Paulo, 30 de dezembro, p. A4.

PALMEIRA, Moacir. 1996. "Política, facções e voto". In: M. Palmeira e M. Goldman (eds.), Antropologia, voto e represen- tação política. Rio de Janeiro: Contra Capa Livraria.

SAUSSURE, Ferdinand de. 1995. Cours de linguistique générale-édition critique préparée par Tullio de Mauro. $3^{\text {ème }}$ ed. Paris: Payot \& Rivages. Grande Bibliothèque Payot (C. Bailly, A. Séchehaye and A. Riedlinger, eds.).

Sucursal de Brasília: 2001a. "Deputados podem ter mais verbas". Folha de $S$. Paulo, 05 de abril, p. A6.

Sucursal de Brasília: 2001b. "Para deputados, esforço e mérito justificam salários". Folha de S. Paulo, 17 de junho, p. A5.

Sucursal de Brasília: 2001c. "Verba de custeio para deputados aumenta 60\%". Folha de S. Paulo, 17 de maio, p. A10.

Sucursal de Brasília: 2001d. "Verba de deputados sobe para R\$32 mil". Folha de $S$. Paulo, 06 de abril, p. A9.

TEIXEIRA, Carla Costa 1998. A honra na política. Decoro parlamentar e cassação de mandato no Congresso Nacional (19491994). Rio de Janeiro: Relume-Dumará/ Núcleo de Antropologia da Política. Coleção Antropologia da Política

VAZ, Lucio. 2001a. "Corregedor diz que repasse de salário é 'grave'". Folha de S. Paulo, 20 de junho, p. A8. .2001b. "Zé de Abreu paga governanta pela Câmara". Folha de S. Paulo, 23 de junho, p. A8. e VILA-NOVA, Carolina. 2001. "Deputados são suspeitos de reter salários de assessores". Folha de S. Paulo, 17 de junho, p. A4.

VILA-NOVA, Carolina. 2001. "Verba extra foi usada para contratar parentes". Folha de S. Paulo, 17 de junho, p. A4. WINCH, Peter. 1958. The idea of social science-and its relation to philosophy. London: Routledge \& Kegan Paul.

WITTGENSTEIN, Ludwig. 1995. Philosophical investigations. London: Basil Blackwell Ltd. 
Resumo

Este artigo descreve as relações políticas no Congresso Nacional brasileiro utilizando o modelo da linguagem. O empreendimento tem sua "inspiração" na idéia lévi-straussiana de que a lingüística teria a chave para a compreensão da sociedade; esta inspiração é, no entanto, desenvolvida em uma outra direção. O artigo faz uma etnografia da política, valendo-se da idéia wittgensteiniana de que o significado de uma palavra é o seu uso em situações concretas; o uso, por sua vez, estaria vinculado a regras. Dentre elas, a mais importante, seria justamente a de que a política é percebida como relações de troca, nos moldes da dádiva descrita por Mauss. Argumenta-se que em certas situações a palavra, ela mesma, é uma prestação, ou seja, faz parte do sistema de trocas. O ponto central do artigo funda-se na percepção da política a partir da relação entre a troca das palavras e a troca das coisas.

Palavras-chave Linguagem, Política, Troca, Poder, Congresso Nacional

\section{Abstract}

Since Lévi-Strauss, anthropologists have been trained to see the exchange relationship identified by Mauss in The Gift as a form of communication. Linguistics, reasoned Lévi-Strauss, holds the key to our understanding of society. This paper develops this anthropological interest in language by pursuing an altogether different approach. Applying Wittgenstein's idea that the meaning of a word is set by its use in actual situations (actual language games), the paper describes the rules for the language games played by politicians in the Brazilian Congress. The most striking of these rules is that politics should be understood as the exchange of material and immaterial things, following the same patterns of gift exchange explored by Mauss. Arguing that, at least in some contexts, the word itself is part of such exchanges, the paper aims to provide an ethnographical investigation of politics as the relationship between the exchange of words and the exchange of things.

Key words Language, Politics, Exchange, Power, Brazilian Congress 